2014

\title{
Discovery Search Tools: A Comparative Study
}

\author{
Mandi Goodsett \\ Cleveland State University, a.goodsett@csuohio.edu
}

Follow this and additional works at: https://engagedscholarship.csuohio.edu/msl_facpub

Part of the Library and Information Science Commons

How does access to this work benefit you? Let us know!

Publisher's Statement

This article is (c) Emerald Group Publishing and permission has been granted for this version to appear here. Emerald does not grant permission for this article to be further copied/distributed or hosted elsewhere without the express permission from Emerald Group Publishing Limited.

\section{Original Citation}

Discovery Search Tools: A Comparative Study. Reference Reviews. 28:6 (2014).

\section{Repository Citation}

Goodsett, Mandi, "Discovery Search Tools: A Comparative Study" (2014). Michael Schwartz Library Publications.

112.

https://engagedscholarship.csuohio.edu/msl_facpub/112

This E-Resource Review is brought to you for free and open access by the Michael Schwartz Library at EngagedScholarship@CSU. It has been accepted for inclusion in Michael Schwartz Library Publications by an authorized administrator of EngagedScholarship@CSU. For more information, please contact library.es@csuohio.edu. 


\title{
Discovery Search Tools: A Review of EBSCO Discovery Service, Primo and Summon
}

\author{
Author \\ Mandi Goodsett is Reference Librarian/Government Documents Coordinator at the James Earl \\ Carter Library of Georgia Southwestern State University, located in Americus, GA, USA.
}

\section{Contact details}

Georgia Southwestern State University James Earl Carter Library

800 Georgia Southwestern State University

Americus, GA 31709

USA

Email: Mandi.Goodsett@gsw.edu

\begin{abstract}
:
Purpose - This review allows librarians to compare three of the major discovery services EBSCO Discovery Service, Ex Libris's Primo, and Serials Solutions's Summon - on the basis of price, content, user experience, features and functionality, and back-end configuration in order to make informed decisions about the best tool for their institutions.

Design/methodology/approach - The comparisons were made through a literature review, study of the vendors' websites, several interviews, and personal usability testing of each tool. Findings - The tools each have their strengths and weaknesses, and a decision of which tool is most appropriate for an institution varies depending on the institution's needs and current situation.
\end{abstract}

Originality/value - A literature review shows that no study has yet been conducted comparing these three discovery tools and few comparative studies of discovery tools have been published recently.

Keywords: Discovery Search Tools; EBSCO Discovery Service; Federated Searching; Primo, Summon

Article Classification: Comparative Review

\section{What is a Discovery Search Tool?}

Increasingly, libraries find themselves competing for the attention of students with big search engines such as Google and Google Scholar, and the result is an increased adoption of tools that allow users to search all library resources from a single search point. In the early $2000 \mathrm{~s}$, the tool that was used by libraries to compete with Google was the federated search, a single entry point which provided results from many databases. While this solution did look and feel more like a Google search, the relevancy ranking, ability to limit, and interface were all less than satisfactory for quality library resource searching. The issue was compounded by the release of Google Scholar in 2004, which provided increased competition with library resource searching (Asher et al 2013).

The situation changed with the release of the first discovery tool, OCLC's WorldCat Local, in 2007, followed closely by Serials Solutions's Summon in 2009 (Asher et al 2013). Both EBSCO Discovery Service and Ex Libris's Primo were then released in 2010 (Rowe 2010). A discovery tool can be defined as "web software that searches journal-article and library-catalog metadata in 
a unified index and presents search results in a single interface" (Fagan et al 2012). Unlike a federated search tool, discovery tools import metadata into one central index and apply a single relevancy ranking and search algorithm to the index to retrieve and display results. These tools are an attempt to meet increasing expectations from patrons for a "Google-like" interface in which all of the library's resources are searched through a single entry point, and the central index of these tools provide more accurate results more quickly than the federated search (Asher et al 2013).

While some librarians believe the discovery search approach to providing library information to users can be misleading, overwhelming, or confusing for patrons, many libraries have adopted discovery search tools to appeal to the preferences of users. Librarians are often the greatest critics of the discovery tool, worrying that undergraduate students who use a discovery tool are getting less appropriate results and are failing to learn how to search a specific database. In addition, studies have shown that graduate students and faculty tend to prefer subject-specific databases for their searching because it allows them to quickly find more relevant results (Thomsett-Scott \& Reese 2012). More and more, however, librarians have had to compromise the encouragement of the more traditional method of finding sources for a way that is quick and simple to use, like Google, which is what the majority of patrons want (Thomsett-Scott \& Reese 2012). Besides providing a more appealing interface, the literature has revealed several other positive aspects of discovery tools, including the ability to search multidisciplinary topics, the option to search multiple databases at once, indications of which subject-specific databases or journals to explore further, and the improved circulation of items in "hidden collections", or collections that are often overlooked by patrons (Thomsett-Scott \& Reese 2012).

Choosing a discovery tool is not a light matter - these tools are significant investments and can result in more work for the library staff both in maintaining the tool and teaching library patrons how to use it. Unfortunately, standards for comparison of discovery tools do not yet exist for librarians, although in the U.S. the National Information Standards Organization (NISO) is currently in the process of creating a list of best practices and standards for discovery tool services through the Open Discovery Initiative (ODI) working group (Kelley 2012). However, until more formal standards exist, informal comparison of the tools is possible through literature reviews, study of the discovery tool providers' websites, and personal usability testing. This review compares three discovery tools - EBSCO Discovery Service (EDS), Ex Libris's Primo, and Serials Solutions's Summon - using these methods of comparison.

\section{Discovery Tool Basics}

The first of the three discovery tools in this review to go live was Serials Solutions's Summon, which was released in 2009. The Summon tool was based on Solr, an open-source search software, and was created as a response to Serials Solutions usability testing in libraries (Rowe 2010). The biggest difference between the Summon discovery tool and others is that Summon does not have a federated search operation; instead, all resources are gathered into one large index, including MARC records from a local OPAC (Rowe 2010). Summon also provides features such as community-sourced recommendations; automated topical refinement suggestions; a database recommender service; the ability to embed widgets; and the integration of research guides, open access materials, digital collections, and institutional repositories in the discovery search results. Serials Solutions is working to improve disciplinary searching within Summon by including discipline assignments at the item level and the ability to embed "discipline-scoped" search boxes and widgets. For libraries that use Summon, there are strong 
community and help functions provided including listservs, a wiki, a support centre, and help webinars.

Primo, a product of Ex Libris, was released in 2010. The primary benefit of Primo as a discovery tool is the ease with which libraries can integrate it with their catalogue metadata if they use Voyager as their ILS. Primo also provides faceted navigation, a temporary "shelf" storage for users, social computing features such as tags and ratings, and direct access to status information and interlibrary loan requests. Users of the Primo discovery tool can easily see details about results or request an item from the catalogue without moving to a new screen. The limiters and interface are extremely customizable for libraries, and there is strong support from Ex Libris during implementation of the tool.

Released in 2010 as well, EBSCO Discovery Service leverages content already on its EBSCOhost servers along with mining its strong relationships with publishers to provide deep, thorough metadata for content (Rowe 2010). Besides strong coverage and deep indexing, EDS provides users of EBSCOhost databases with a familiar interface, reducing the amount of time librarians must spend familiarizing library staff, faculty, and students with the new tool. EDS is also the only tool to offer instant access to full text from the results screen without navigation to a link resolver page. Features of EDS include the ability to save search strings and create a personal folder, subject-specific profiles, persistent links, full text language translations, and federated searching that can include external dynamic results such as Flikr, YouTube, or Google Books.

\section{Comparing Discovery Tools}

\section{Price}

None of the tools compared here provide detailed pricing information to the public. In most cases, pricing is based on the FTE and the type of library or institution. EDS operates as an addon service, allowing libraries to include additional services such as enhanced book data, an A-to$\mathrm{Z}$ listing service, and the EBSCO linking service for additional cost. The cost of including federated searching also varies depending on the number of connections to non-EDS, nonEBSCOhost resources (Brunning \& Machovech 2010b). Primo offers the option for libraries to host the discovery service themselves or have the tool hosted by Ex Libris, which has an effect on the pricing of the tool. Summon's rates include an unlimited number of special collections or institutional repositories to be added to its central index, so its rates are only affected by FTE and type of institution.

\section{Content}

Coverage can be tricky between the discovery tools because none of the providers allow access to their own metadata for the indexes of the other discovery tools, which means that no discovery tool harvests strong metadata from all providers that exist. However, there is a considerable amount of overlap in the content indexed by each discovery tool, and most provide access to a listing of all the sources available in their index. These lists can be overwhelming, often numbering in the thousands, and the depth of indexing for the resources listed is often unclear (Kelley 2012). Serials Solutions' provides a complimentary service that compares the contents of their index to an individual library's holdings, but a comparison of the amount and depth of content coverage is still difficult in many cases because the information each vendor provides about its coverage is formatted differently, and the sheer magnitude of the indexed material is often too much to evaluate. This is an issue being addressed by the ODI because, in many cases, 
in a library's decision about which tool to choose "the key question is which of the products might offer the best coverage for a given library's subscriptions" (Kelley 2012).

Summon offers a list of all the databases and serials titles in its index to interested libraries and, as mentioned above, will even compare its index to a library's collection for free. Content in a Summon search can include open access articles, digital collections, institutional repositories, and results from consortia libraries. Because of Summon's unique central index, users can access records for content that is not part of the library's collection but does exist in the index (the function is called "Beyond the Library"). While Serials Solutions does not have an agreement with EBSCO for EBSCOhost metadata, their publisher agreements cover the majority of EBSCO material, although the metadata included may not be as thorough (Brunning \& Machovec 2010c). Perhaps Summon's greatest advantage in the realm of content is its ability to display and highlight local and special collections; therefore, "libraries that get the biggest benefit from Summon are those that have either a large amount of subscribed electronic content or special collections or both" (Brunning \& Machovec 2010c).

Primo also offers a large quantity of material in its index, as well as the ability to include federated results such as consortia material, content in HathiTrust, and other special collections. Out of the three, federated search content is highlighted most successfully in this tool; the results of federated searching appear at the top of the screen and are easily seen and accessible. Primo tries to offer a wide variety of material, including non-journal sources, making its index broad in its coverage (Brunning \& Machovec 2010a).

EBSCO Discovery Service's coverage is bolstered by its access to full indexing of EBSCOhost databases and partner databases such as NewsBank, Readex, LexisNexis, and Alexander Street Press (Brunning \& Machovec 2010b). What isn't covered in these sources can be included in EBSCO's federated search tool, called EBSCHOhost Integrated Search (EHIS). Beyond nonindexed collections, EDS's federated search can display external results such as Flikr, YouTube, Google Books, and LibGuides. These federated search results are displayed in a right-hand side panel, which, among the three tools, is the least successful at highlighting these additional resources. Despite the weakness of EDS's federated search result placement, EDS provides the strongest coverage in its index, especially for libraries that use many EBSCOhost databases.

There have been questions by librarians about the neutrality of the content displayed in search results using a discovery tool (Kelley 2012). If a particular vendor is providing the discovery tool capabilities, are the sources from that vendor ranked higher in a results list? All the tools reviewed here claim to be completely unbiased in their relevancy ranking algorithms. However, some full-text providers refuse to make their full-text available for indexing in any discovery service for fear that their data will have a low profile in search results because of "branding policies" (Kelley 2012). This means that even if the information presented to patrons in a results list through a discovery tool search is not biased, it is sometimes incomplete. Both Serials Solutions and EBSCO have worked with abstracting and indexing providers to better integrate that metadata in their indexes, but EBSCO's preexisting relationships with providers make it possible for EDS to have stronger indexing capabilities (Kelly 2012).

\section{User Experience}

An element of the Summon user interface that appeared particularly useful was its temporary folder function; along the bottom of the screen, there is an option to save any resource in the results list to a folder that can be perused during a search session. Another strength of Summon is its autocomplete function, as well as the display of status, location, and call number for library catalogue material on the results screen. Full text links do not bring users directly to the full text 
of an article, but to the link resolver, which seems to work smoothly with the Summon interface, regardless of the provider. Authentication prompts do not interrupt the flow of browsing in the results list and are only shown after clicking on a link to online content. One function that is missing from the Summon limiters is the ability to limit to a particular database or see the number of results from various publications or vendors within the index (as is available in EDS). Visually, Summon is one of the most Google Scholar-like interfaces and very aesthetically pleasing (Rowe 2010).

Primo's interface is also very Google Scholar-like. The tool also has an "e-shelf" function which, like Summon, allows users to save particular sources temporarily; users can also save queries and even set up an RSS feed for new results to a query. Similar to the autocomplete function, Primo has a "Did you mean?" function for search queries. One of the most appealing features of Primo is the fact that users can access additional information about a source or directly request a source from the library catalogue without having to leave the results page to go to a new screen. However, as with Summon, links to full text in Primo do not go directly to the PDF or HTML full text but to a link resolver. The icons for results in Primo are more intuitive than in Summon or EDS, perhaps promoting ease of browsing for less experienced library users. The authentication point in Primo varies by institution, with some libraries requiring users to log in to see all results and others with an authentication point after the link for online material is clicked. A search for a specific database in Primo is very effective, displaying the database at the top of the results list in the federated search box. Federated search results are very prominently displayed in a box at the top of the results list in this tool - perhaps most successfully out of the three tools.

The interface in EBSCO Discovery Service might be the most intuitive and familiar to users because it is very similar to the interface for any EBSCOhost database. As with the EBSCOhost databases, users can save results to a folder, which can be made permanently available for users who create an account (instead of disappearing after a search session). EDS is the only tool that allows instant access to full-text material from a link in the results list, although users may be faced with an authentication point after clicking on the link. A search for a specific database in EDS is not successful in most cases; however, EDS is the only tool that allows users to limit by database and journal, a useful tool for users who may need guidance to a more discipline-specific database but be unsure where to start. The limiters in EDS can be set as a default to be collapsed or un-collapsed in the results screen depending on the number of limiters available, making the screen less cluttered. While there is much to be said for the familiarity of the interface in EDS, there are a few weaknesses: the federated search material in EDS is often ignored or unnoticed by users because of its placement on the results screen, and the icons for source types are less clear than in other discovery tools (Fagan et al 2012).

\section{Features and Functionality}

One of the most significant factors in the effectiveness of a discovery tool is the quality of its relevancy ranking formula, since the default relevancy ranking often determines the way students will value the information presented. Many students using the discovery tool lack the skills to evaluate the information in the results list, leading them to place great significance on the way the tool ranks results. Unfortunately, the actual algorithms used by EBSCO, Ex Libris, and Serials Solutions are proprietary and therefore not available to be compared, making it difficult to decide which is most effective for a particular library's needs (Asher et al 2013). EBSCO has released some of the guidelines of its relevancy ranking on its website; subject headings from controlled vocabulary are ranked highest, then article titles, author keywords, keywords in the 
abstract, and keywords from the full-text (from exact to partial). The ranking is also guided by the density of the keyword instances in the source, or the number of times it appears per total number of words, which addresses the issue of ranking sources that include indexed full-text versus just the abstract. Overall, EDS seems to have the strongest relevancy ranking with Summon and then Primo coming in close behind.

In addition to the relevancy ranking, the functionality of a discovery tool also rests heavily on its ability to provide intuitive limiting options and facets. All of the tools reviewed here allow libraries to manipulate the limiting facets that appear in a search and, to some extent, how the facets that do appear are displayed in the interface. With Summon, libraries can decide how many options in each facet will display before the rest are hidden in a "more..." link. Libraries can also provide the option for users to limit their search results to a certain format in the initial search box before beginning the search in the discovery tool, which is especially helpful knowing that a good number of students won't use the limiters once they reach the results page (Thomsett-Scott \& Reese 2012). There is a publication date slider available as a limiter that guides the user to limit by year in an easier way than the unguided date sliders in the other two tools. Limiters can automatically be set by librarians for the basic search (e.g., no newspaper articles or book reviews), but those limiters are only applied automatically if a search is performed from the main search bar on the library homepage, not internally in Summon during a search session.

Primo's limiters are also highly customizable by library staff. Libraries have the option of including a limiter that leaves out items that are checked out, although in usability testing on library websites this function did not always work. For patrons who want a highly refined search, clicking on "more" in any of the limiting facets brings them to a widget that allows exclusion or inclusion of the limiters in that facet at the same time. Primo also has strong social-media-type elements, such as tagging, user ratings, and user reviews; the social media elements of Primo are stronger than in the other tools.

Besides having a familiar interface, EBSCO Discovery Service allows libraries to customize the discovery service interface to blend more seamlessly with the rest of the library online experience. While all the tools allow for some interface customization, EDS seems to allow for the most library branding within the discovery tool (Brunning \& Machovec 2010b). As with the other tools, customization of limiters present is possible in EDS, as well as the presence of chat or help widgets. Besides the library branding capabilities, however, the interface design customizability in EDS is limited because of the way EDS imitates the EBSCOhost databases in its design.

All three services provide a mobile interface for library users, although the success of the mobile interface varies between tools. Primo seems to have the strongest, most intuitive mobile application with easy navigation within an uncluttered interface. Many of the limiters and additional record information is available in Primo's application without the user leaving the current page. Both Summon and EBSCO Discovery Service also have fairly strong mobile applications, although both require users to leave the results screen to limit searches, making navigation a little more cumbersome. In EDS, the list of results continues to grow as the user scrolls, eliminating the need to move to a new page but making it difficult to add limiters (which are at the top of the long list) without scrolling all the way to the top of the page. It's also not possible to see the availability of library catalogue material from the results screen in the EDS mobile application without moving to a new screen. In Summon, the mobile application is 
visually appealing, but reverts to the normal computer interface once the user moves to a new page in the results list.

\section{Back End Configuration}

Regardless of the tool chosen, back-end configuration of the discovery tool can be timeconsuming and frustrating. Challenges a library might encounter include issues configuring the tool; synchronizing it with the link resolver, ILS, and ERM already in place; or integrating the catalogue into the index to be used for search results. These initial issues are compounded by the necessity for continual updates to the index and other maintenance required by library staff. Not surprisingly, a major factor of consideration in choosing a discovery tool is its ease of maintenance and ability to easily integrate with the library's current ILS. The burden of implementing and maintaining these tools vary between institutions and between tools.

To use Summon, libraries are in no way obligated to change any of their current systems; however, many libraries have found the transition to be easier when they had already switched to the Serials Solutions link resolver and/or A-Z journal listing service. One librarian reported that the library decided to reconfigure their EMS from the Ex Libris product they had been using to a Serials Solutions product because the EMS is "tightly integrated as a back-end to the Summon system" (Boston 2013). The library also had a few difficulties at first linking from Summon to its Ex Libris link resolver, but those issues were quickly ironed out (Boston 2013). The implementation of the tool is completed through the efforts of both librarians at the institution and employees of the vendor, a common implementation set-up among the tools. The implementation of the tool can be time-consuming and requires the attention and hard work of librarians with deep knowledge of the library's ILS and metadata, but after implementation the tool is fairly easy to maintain (Beisler 2013). Users of Summon reported very reliable and consistent support services when problems arose in implementation and beyond (Boston 2013).

Not surprisingly, libraries with Ex Libris products found Primo especially easy to implement, although some minimal changes in configuration were required even with products provided by Ex Libris (Hyland-Carver 2013). Primo can be used as a locally installed tool or it can be hosted by Ex Libris, which changes the implementation process. Overall, the implementation process and maintenance of Primo seems a little more involved, with one library (which is, granted, very large) needing to hire a full-time employee to maintain upkeep of Primo (Norman 2013). However, the support of the Ex Libris Primo Support Team is strong and employees from Ex Libris are very involved in helping with implementation (Norman 2013). Once again, matching all library systems by switching to the discovery tool's vendor is not necessary, but it does make implementation easier.

Libraries with many EBSCOhost databases will find implementation of EDS to be more straightforward, although the libraries interviewed said that the integration of all sources, including library catalogue sources, was stress-free overall. EBSCO support is strong throughout the implementation process and continues as the institution maintains the discovery tool (while comparison is difficult, EDS seems to provide the most well-supported discovery tool implementation process). The "actual maintenance [of EDS] is negligible" after implementation, with the biggest time commitment for the librarians being "educating librarians, faculty, and students about the nature of the discovery layer" (Virtue 2013). The theme throughout the literature is that regardless of the work and money put into implementing any one of these incredible tools, the biggest objectors continue to be librarians, and it often falls to the librarians responsible for configuring the tool to defend its usefulness in various research situations to their colleagues. 


\section{Conclusion}

While there is no obviously superior discovery tool providing a perfect fit for all libraries, the comparisons described here offer libraries of various types and with various needs the ability to make an educated decision about the best discovery tool for their particular institution.

Before choosing a discovery tool, your library might want to ask:

- How much of the library's current content is covered by each of these discovery tools' indexes?

- Does the library want to emphasize local collections?

- Does the library mostly use products (e.g., ILS, link resolver, etc.) from a particular vendor? Are you happy with the service you've received so far from that vendor? Would it be possible to change your library systems to accommodate a discovery service? Do you want to?

- How much customization of the searching interface would you like? How important are things such as the ability to save searches or to have social media elements (e.g. tagging)?

- How much technological knowledge does your staff have? How much support would your current library staff be able to provide for the implementation of the discovery tool?

Choosing a discovery tool can be a time-consuming, difficult process. However, all the libraries interviewed found the overall experience of implementing and providing the discovery tool service to be positive, regardless of the amount of extra work and budgetary concerns involved. Discovery tools provide users with a search unlike any other previously available simple and straightforward (from the user perspective), but also with high quality sources populating the search results. Surprisingly, often the greatest hurdle in adopting a discovery tool for your library isn't choosing the best tool for your institution, but making clear to your library staff and campus community that the discovery tool can be extremely valuable when used in the proper way. A strong, carefully chosen discovery tool can be the first step in convincing your community of the value of a discovery tool to library research in a Google-centric, quickly evolving information landscape.

\section{References}

Asher, A. D. et al (2013) Paths of Discovery: Comparing the Search Effectiveness of EBSCO Discovery Service, Summon, Google Scholar, and Conventional Library Resources College \& Research Libraries, vol. 74, no. 5, pp.464-488

Beisler, M. (2013) Serials Solutions Summon Interviewed by Mandi Goodsett [phone] December 3, 2013

Boston, G. (2013) Serials Solutions Summon Interviewed by Mandi Goodsett [phone] November 26, 2013

Brunning, D. \& Machovec, G. (2010a) An Interview with Nancy Dushkin, VP Discovery and Delivery Solutions at Ex Libris, Regarding Primo Central The Charleston Advisor, vol. 12, no. 2, pp.58-59

Brunning, D. \& Machovec, G. (2010b) An Interview with Sam Brooks and Michael Gorrell on the EBSCOhost Integrated Search and EBSCO Discovery Service The Charleston Advisor vol. 11 , no. 3, pp.62-65

Brunning, D. \& Machovec, G. (2010c) Interview about Summon with Jane Burke, Vice President of Serials Solutions The Charleston Advisor vol. 11, no. 4, pp.60-62

Cunetto, S. (2013) EBSCO Discovery Service Interviewed by Mandi Goodsett [phone] December 5,2013 
Fagan, J.C. et al (2012) Usability Test results for a Discovery Tool in an Academic Library Information Technology and Libraries vol. 31, no. 1, pp.83-112

Hyland-Carver, M. (2013) Ex Libris PRIMO Interviewed by Mandi Goodsett [e-mail] December 3, 2013

Kelley, M. (2012) Coming into Focus: Web-Scale Discovery Services Face Growing Need for Best Practices Library Journal vol. 137, no. 17, pp.34-40

Mcgough, C. (2013) EBSCO Discovery Service Interviewed by Mandi Goodsett [phone] November 20, 2013

Norman, M. (2013) Ex Libris PRIMO Interviewed by Mandi Goodsett [e-mail] December 6, 2013

Rowe, R. (2010) Web-Scale Discovery: A Review of Summon, EBSCO Discovery Service, and WorldCat Local The Charleston Advisor vol. 12, no. 1, pp.5-10

Thomsett-Scott, B. \& Reese, P. E. (2012) Academic Libraries and Discovery Tools: A Survey of the Literature College \& Undergraduate Libraries vol. 19, no. 2, pp.123-143

Virtue, A. (2013) EBSCO Discovery Service Interviewed by Mandi Goodsett [phone] November 25,2013 